\title{
Single center experience with the Sorin Bicarbon prosthesis: A 17-year clinical follow-up
}

\author{
Michele Celiento, MD, ${ }^{a}$ Luca Filaferro, MD, ${ }^{a}$ Aldo D. Milano, MD, PhD, FECTS, ${ }^{b}$ \\ Gerardo Anastasio, MD, ${ }^{\mathrm{a}}$ Gabriele Ferrari, MD, ${ }^{\mathrm{a}}$ and Uberto Bortolotti, MD, FACC, FECTS ${ }^{\mathrm{a}}$
}

Objective: To evaluate the long-term results of aortic valve replacement (AVR) and mitral valve replacement (MVR) with the Sorin Bicarbon prosthesis (SBP).

\begin{abstract}
Methods: Five hundred seven patients (306 men, 201 women), mean age $62 \pm 10$ years (range, 21-86 years), received an SBP between 1994 and 2000; AVR was performed in $344(67 \%)$ and MVR in $163(33 \%)$. The main concomitant procedure was coronary artery grafting in 79 patients $(16 \%)$. Follow-up was $99 \%$ complete; mean follow-up was $12.7 \pm 4.0$ years with a cumulative duration of follow-up of 6475 patient-years in the entire group (4348 patient-years for AVR and 2124 patient-years for MVR).
\end{abstract}

Results: Hospital mortality was $2.7 \%$ (AVR, 2.03\%; MVR, 4.3\%). There were 169 late deaths (AVR, 128; MVR, 41). Actuarial survival at 17 years is $49.7 \% \pm 5.3 \%$ for AVR and $62.0 \% \pm 6.1 \%$ for MVR. At the last follow-up, 310 survivors (199 AVR, 111 MVR) are in New York Heart Association functional class I or II. At 17 years, actuarial freedom from valve-related deaths, embolism, and bleeding is $89.8 \% \pm 4.8 \%$, $85.8 \% \pm 5.4 \%$, and $96.2 \% \pm 1.2 \%$ after AVR, and $91.9 \% \pm 3.9 \%, 96.3 \% \pm 1.8 \%, 95.0 \% \pm 2.9 \%$ after MVR. Reoperation was required in 5 patients with AVR (thrombosis in 4 and perivalvular leak in 1). Actuarial freedom from reoperation is $98.1 \% \pm 0.8 \%$ after AVR and $100 \%$ after MVR; freedom from endocarditis is $100 \%$ after AVR and $99.2 \% \pm 0.7 \%$ after MVR. No cases of intrinsic structural valve failure were observed.

Conclusions: The SBP has shown excellent results in terms of clinical improvement and freedom from valve-related complications, even up to 17 years after AVR and MVR. It therefore seems to be a safe option whenever a mechanical prosthesis is needed. (J Thorac Cardiovasc Surg 2014;148:2039-44)

Bileaflet prosthetic valves have been in clinical use for more than 4 decades and have widespread acceptance as mechanical cardiac valve substitutes; they are considered hemodynamically superior to tilting disc valves. ${ }^{1-4}$ The Sorin Bicarbon prosthesis (SBP) (Sorin Biomedica, Saluggia, Italy) has been available since 1990 and has shown good early and medium-term results. ${ }^{5-10}$ However, long-term follow-up data are limited and may be derived mainly from 1 multicenter study reporting a 15-year follow-up of 1704 patients from 12 European centers. ${ }^{11}$ In this article, we report on clinical evaluation of the SBP based on the experience of a single center with a maximum follow-up of more than 17 years.

\section{MATERIALS AND METHODS}

A retrospective evaluation of patients receiving an SBP at our institution from 1994 to 2000 was performed. Patients who had undergone isolated

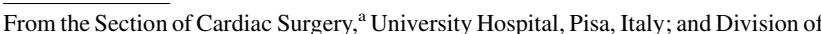
Cardiac Surgery, ${ }^{\mathrm{b}}$ University of Verona, Verona, Italy.

Disclosures: Authors have nothing to disclose with regard to commercial support.

Received for publication Aug 8, 2013; revisions received Oct 21, 2013; accepted for publication Nov 7, 2013; available ahead of print Dec 11, 2013.

Address for reprints: Uberto Bortolotti, MD, FACC, FECTS, Sezione Autonoma di

Cardiochirurgia Universitaria, Università di Pisa, Via Paradisa, 2, 56124 Pisa, Italy

(E-mail: uberto.bortolotti@med.unipi.it).

$0022-5223 / \$ 36.00$

Copyright (c) 2014 by The American Association for Thoracic Surgery

http://dx.doi.org/10.1016/j.jtcvs.2013.11.015
}

aortic valve replacement (AVR) or isolated mitral valve replacement (MVR) were considered; patients with double valve replacement or who received an SBP in association with other types of prostheses were excluded. This study was approved by our Institutional Ethical Committee and informed consent to participate to the study and use of data was obtained from all long-term survivors.

\section{Valve Design}

The SBP is a mechanical prosthesis with 2 leaflets made of pyrolitic carbon with a curved profile. The leaflets are included in a housing of titanium alloy which, together with the sewing ring, is coated with a layer of carbon (Carbofilm). The leaflets, which open up to $80^{\circ}$ from a $20^{\circ}$ horizontal axis, move through an innovative rolling hinge mechanism, which provides low turbulence, partitioning of the flow into 3 equivalent bloodstreams, and a full washing effect through the cardiac cycle. ${ }^{12,13}$

\section{Patient Characteristics}

A total of 507 patients were reviewed (Table 1). There were 306 men $(60 \%)$ and 201 women $(40 \%)$; the mean age was $62 \pm 10$ years (range, 21-86 years). AVR was performed in 344 patients $(67 \%)$ and MVR in $163(33 \%)$. The predominant valve pathology was calcific degeneration for AVR and rheumatic disease for MVR. Preoperatively, most patients were in New York Heart Association (NYHA) functional class II and III; mean NYHA class was $2.5 \pm 0.5$ for AVR and $2.6 \pm 0.5$ for MVR; $74 \%$ were in sinus rhythm and $26 \%$ in chronic atrial fibrillation. Mean left ventricular ejection fraction was $52 \% \pm 9 \%$. Chronic renal failure (serum creatinine $>2.0 \mu \mathrm{mol} / \mathrm{L}$ ) was present in 13 patients $(2.5 \%)$ and moderate or severe chronic obstructive pulmonary disease in $28(5.5 \%)$. Mean logistic EuroSCORE (European System for Cardiac Operative Risk Evaluation) was 5.1\% $\pm 0.5 \%$ (range, $1.5 \%-35 \%$ ) for AVR and $6.7 \% \pm 0.8 \%$ (range, $1.5 \%-38 \%$ ) for MVR. Urgent surgery 


\section{Abbreviations and Acronyms \\ AVR = aortic valve replacement \\ EuroSCORE $=$ European System for Cardiac \\ Operative Risk Evaluation \\ INR = international normalized ratio \\ MVR = mitral valve replacement \\ NYHA $=$ New York Heart Association \\ SBP $\quad=$ Sorin Bicarbon prosthesis}

was performed in 17 patients $(3 \%)$ and $60(12 \%)$ underwent reoperation. In 137 cases $(27 \%)$, other procedures were associated with valve replacement, mainly coronary artery bypass grafting (64 patients, 19\%), replacement of the ascending aorta (13 patients, 4\%), and aortic annulus enlargement (11 patients, $3 \%$ ) during AVR and tricuspid annuloplasty (22 patients, 13\%) during MVR.

\section{Surgical Technique}

A uniform technique was used throughout the series. Operations were performed through a median sternotomy; in patients undergoing reoperation, the chest was entered through a repeat sternotomy. Cardiopulmonary bypass was established with the ascending aorta and single or bicaval venous cannulation with moderate systemic hypothermia $\left(28-32^{\circ} \mathrm{C}\right)$. The heart was arrested with antegrade cold blood cardioplegia into the aortic root or coronary ostia maintaining topical cooling throughout the procedure; retrograde cardioplegia was only occasionally used. The left ventricle was vented through the right upper pulmonary vein for AVR cases. Prostheses were implanted using $2 / 0$ nonabsorbable sutures reinforced by Teflon felts placed in a subannular position for AVR after careful annular debridement from calcium deposits when present; for MVR, the posterior mitral leaflet with its chordal attachments was completely or partially left in place in all cases and Teflon pledgets were placed in a supraannular everting position. Prostheses were mainly oriented with 1 hinge facing the interventricular septum for AVR and in the antianatomic position for MVR. Distal coronary anastomoses were always performed before valve replacement. Prosthetic sizes are shown in Table 1. All patients were given subcutaneous heparin starting from the first postoperative day. Sodium warfarin therapy was started after extubation and removal of chest drains, usually on postoperative day 2 ; when a target international normalized ratio (INR) of 2.5 for AVR (range, 2-3) and 3 for MVR (range, 2.5-3.5) was reached, heparin was suspended. No patient was routinely given antiplatelet drugs.

\section{Data Acquisition and Follow-up}

Baseline data were retrieved from our local database. After discharge, all patients were entered in our follow-up protocol, which includes serial clinical controls at $1,3,6$, and 12 months and then on a yearly basis. Patients were encouraged to refer to our outpatient clinic for evaluation of clinical status and valve performance and to discuss by direct interview all possible postoperative complications, which were assessed according to well-established guidelines. ${ }^{14}$ Those unable to come back to our hospital were contacted by phone and additional information was obtained from relatives or referring physicians when necessary. The follow-up of the current series was closed in December 2012 and was $99 \%$ complete with only 5 patients untraced. Cumulative duration of follow-up is 6475 patient-years in the entire group, 4348 patient-years for AVR and 2124 patient-years for MVR; mean follow-up is $12.7 \pm 4.0$ years ranging from 0.2 to 17.7 years.

\section{Statistical Analysis}

Data are presented as means \pm standard deviation and as simple percentages. Overall survival and freedom from valve-related complications were determined by Kaplan-Meier actuarial analysis and expressed as percentages of patients who were event free \pm standard error. The linearized rate of postoperative complications was expressed as $\%$ /patient-year. Statistical analysis was performed using commercially available SPSS software, version 17.0 (SPSS, Inc., Chicago, Ill).

\section{RESULTS \\ Operative Mortality and Survival}

The incidence of major postoperative complications is listed in Table 2 . There were 14 early deaths $(<30$ days $)$ with a cumulative operative mortality of $2.7 \%$; mortality was $2 \%$ (7 patients) for AVR and 4\% (7 patients) for MVR. Causes of hospital mortality were cardiac and multiorgan failure in 10 patients and sepsis in 4 patients. There were 169 late deaths, 128 after AVR and 41 after MVR; of these, 22 were considered as valve-related, with a linearized incidence of $0.34 \% \pm 0.07 \%$ /patient-year; these deaths were caused by embolism in 8 patients (6 AVR and 2 MVR), hemorrhage in 5 (4 AVR and 1 MVR), prosthesis thrombosis in 3 (all AVR), endocarditis in $1 \mathrm{MVR}$, periprosthetic leak in $1 \mathrm{MVR}$, and 4 sudden unexpected deaths ( $3 \mathrm{MVR}, 1 \mathrm{AVR}$ ). Actuarial survival is $81 \% \pm 2 \%$ at 10 years and $50 \% \pm 3 \%$ at 17 years after AVR (Figure 1) and $83 \% \pm 3 \%$ at 10 years and $62 \% \pm 6 \%$ at 17 years after MVR (Figure 2). Actuarial freedom from prosthesis-related deaths is $96 \% \pm 2 \%$ at 10 years and $90 \% \pm 5 \%$ at 17 years for AVR (Figure 1) and $99 \% \pm 1 \%$ at 10 years and $92 \% \pm 4 \%$ at 17 years for MVR (Figure 2). Of the 316 current survivors reevaluated (202 AVR and 114 MVR), 172 are in NYHA class I, 138 are in class II, and 6 are in class III; the mean postoperative NYHA class is $1.4 \pm 0.6$ for AVR $(P<.001)$ and $1.5 \pm 06$ for MVR $(P<.001)$. A total of 247 patients are in sinus rhythm (161 AVR and 86 MVR) and 51 are in chronic atrial fibrillation (31 AVR and 20 MVR); 18 patients have a permanent pacemaker. The mean INR value at last follow-up was $2.6 \pm 0.5$ for AVR patients and $2.7 \pm 0.4$ for MVR patients.

\section{Embolism}

A total of 22 embolic episodes were recorded with a linearized incidence of $0.34 \% \pm 0.07 \%$ /patient-year; 17 occurred after AVR $(0.39 \% \pm 0.09 \% /$ patient-year $)$ and 5 after MVR $(0.24 \% \pm 0.11 \% /$ patient-year $)$. The mean age was $63 \pm 10$ years for AVR patients and $64 \pm 8$ years for MVR patients; 1 of the AVR patients and 2 of the MVR patients were in atrial fibrillation. A fatal cerebral embolism occurred in 8 patients (6 AVR and 2 MVR) at a mean time from operation of $9.7 \pm 4.5$ years and with a linearized incidence of $0.12 \% \pm 0.04 \%$ /patient-year; of the 14 patients with a nonfatal embolism, 5 had permanent sequelae. Last mean INR available in patients with an embolic event was $2.9 \pm 0.5$ for AVR and $2.6 \pm 0.4$ for MVR. 
TABLE 1. Summary of clinical and surgical data

\begin{tabular}{|c|c|c|c|}
\hline & $\operatorname{AVR}(\%)$ & $\operatorname{MVR}(\%)$ & Total $(\%)$ \\
\hline No. of patients & $344(67)$ & $163(33)$ & $507(100)$ \\
\hline \multicolumn{4}{|l|}{ Gender } \\
\hline Male & $237(69)$ & $68(42)$ & $306(60)$ \\
\hline Female & $105(31)$ & $95(58)$ & $201(40)$ \\
\hline Mean age $(y \pm S D)$ & $62 \pm 10$ & $62 \pm 9$ & $62 \pm 10$ \\
\hline \multicolumn{4}{|l|}{ Valvular lesion } \\
\hline Stenosis & $102(30)$ & $39(24)$ & $141(28)$ \\
\hline Incompetence & $85(25)$ & $75(46)$ & $160(32)$ \\
\hline Stenosis and incompetence & $157(45)$ & $49(30)$ & $206(40)$ \\
\hline \multicolumn{4}{|l|}{ Valve pathology } \\
\hline Calcific degeneration & $235(68)$ & $15(9)$ & $250(49)$ \\
\hline Rheumatic & $62(18)$ & $112(69)$ & $174(34)$ \\
\hline Myxomatous degeneration & $36(10)$ & $21(14)$ & $57(11)$ \\
\hline Endocarditis & $2(1)$ & $3(1)$ & $5(1)$ \\
\hline Prosthetic dysfunction & $9(3)$ & $9(6)$ & $18(4)$ \\
\hline Other & - & $3(1)$ & $3(1)$ \\
\hline \multicolumn{4}{|l|}{ NYHA class } \\
\hline II & $169(49)$ & $65(40)$ & $234(46)$ \\
\hline III & $175(51)$ & $97(59)$ & $272(53)$ \\
\hline IV & - & $1(1)$ & $1(1)$ \\
\hline \multicolumn{4}{|l|}{ Rhythm } \\
\hline Sinus & $309(89)$ & $65(40)$ & $374(74)$ \\
\hline Atrial fibrillation & $35(10)$ & $98(60)$ & $133(26)$ \\
\hline Pacemaker & $5(1)$ & - & $5(1)$ \\
\hline Renal failure & $9(3)$ & $4(2)$ & $13(3)$ \\
\hline $\begin{array}{l}\text { Chronic obstructive pulmonary } \\
\text { disease }\end{array}$ & $21(6)$ & $7(4)$ & $28(6)$ \\
\hline EuroSCORE $(\%)$ & $5.1 \pm 0.5$ & $6.7 \pm 0.8$ & $5.6 \pm 6.4$ \\
\hline \multicolumn{4}{|l|}{ Associated procedures } \\
\hline Coronary artery bypass graft & $64(19)$ & $15(9)$ & $79(16)$ \\
\hline Replacement ascending aorta & $13(4)$ & - & $13(3)$ \\
\hline Aortic annulus enlargement & $11(3)$ & - & $11(3)$ \\
\hline Tricuspid annuloplasty & $12(3)$ & $22(13)$ & $34(7)$ \\
\hline \multicolumn{4}{|l|}{ Prosthetic size } \\
\hline $19 \mathrm{~mm}$ & $1(1)$ & - & $1(1)$ \\
\hline $21 \mathrm{~mm}$ & $62(18)$ & - & $62(12)$ \\
\hline $23 \mathrm{~mm}$ & $159(46)$ & - & $159(31)$ \\
\hline $25 \mathrm{~mm}$ & $95(28)$ & $2(1)$ & $97(19)$ \\
\hline $27 \mathrm{~mm}$ & $23(7)$ & $59(36)$ & $82(16)$ \\
\hline $29 \mathrm{~mm}$ & $4(1)$ & $71(44)$ & $75(15)$ \\
\hline $31 \mathrm{~mm}$ & - & $25(15)$ & $25(5)$ \\
\hline $33 \mathrm{~mm}$ & - & $6(4)$ & $6(1)$ \\
\hline
\end{tabular}

$\overline{A V R}$, Aortic valve replacement; $M V R$, mitral valve replacement; $S D$, standard deviation; NYHA, New York Heart Association; EuroSCORE, European System for Cardiac Operative Risk Evaluation.

\section{Valve Thrombosis}

Six patients experienced prosthetic thrombosis at a mean interval of $10 \pm 5$ years from AVR with an incidence of $0.09 \% \pm 0.04 \%$ /patient-year; in this group, the last available mean INR was $2.5 \pm 0.2$. The mean age was $65 \pm 8$ years and 1 patient was in atrial fibrillation. Four patients were reoperated and there were 3 deaths because of multiorgan failure. No known case of prosthetic thrombosis occurred after MVR. Actuarial freedom from thromboembolism, including embolic episodes and valve thrombosis, is $96 \% \pm 1 \%$ at 10 years and $86 \%$ $\pm 5 \%$ at 17 years for AVR patients and $98 \% \pm 1 \%$ at 10 years and $96 \% \pm 2 \%$ at 17 years for MVR patients (Figure 3).

\section{Hemorrhages}

Anticoagulant-related hemorrhages were observed in 13 patients with a linearized incidence of $0.20 \% \pm$ $0.06 \%$ /patient-year. They involved 10 patients with AVR $(0.23 \% \pm 0.07 \% /$ patient-year) and 3 with MVR $(0.14 \%$ $\pm 0.08 \%$ /patient-year); 5 patients (4 AVR and 1 MVR) had a fatal hemorrhage. This complication occurred at a mean time since operation of $9.1 \pm 5.3$ years when the least available mean INR was $2.5 \pm 0.3$ for AVR patients and $2.6 \pm 0.4$ for MVR patients. Actuarial freedom from anticoagulant-related hemorrhages is $97 \% \pm 1 \%$ at 10 years and $96 \% \pm 1 \%$ at 17 years for AVR patients and $100 \%$ at 10 years and $95 \% \pm 3 \%$ at 17 years for MVR patients.

\section{Perivalvular Leak}

A periprosthetic leak was observed in 1 patient 3 years after AVR giving an incidence of $0.02 \pm 0.02 \%$ patientyear; this patient died at reoperation in low output state. Actuarial freedom from this complication is $99 \% \pm 1 \%$ at 10 and 17 years after AVR and $100 \%$ at 10 and 17 years after MVR.

\section{Endocarditis}

One case of endocarditis was recorded 9 years after MVR with a linearized incidence of $0.05 \% \pm 0.05 \%$ /patientyear. This patient died of sepsis without reoperation. Actuarial freedom from endocarditis after AVR is $100 \%$ at 10 and 17 years and after MVR is $99 \% \pm 1 \%$ at 10 and 17 years, respectively.

\section{Reoperation}

Five patients required reoperation at a mean interval of $7 \pm 5$ years from AVR giving an incidence of $0.11 \% \pm$ $0.05 \% /$ patient-year. Causes of reoperation were prosthetic thrombosis in 4 and periprosthetic leak in 1. No patient with MVR underwent reoperation and no cases of intrinsic SBP failure were observed. Actuarial freedom from reoperation is $99 \% \pm 1 \%$ at 10 years and $98 \% \pm 1 \%$ at 17 years for AVR patients and $100 \%$ at 10 and 17 years for MVR patients.

\section{Valve-Related Complications}

Overall, valve-related complications occurred in 47 patients with an incidence of $0.73 \% \pm 0.11 \%$ /patient-year in the entire series; $35(0.80 \% \pm 0.14 \% /$ patient-year $)$ were observed after AVR and 12 after MVR $(0.56 \% \pm$ $0.16 \% /$ patient-year). Causes were as follows: embolism 
TABLE 2. Linearized incidence of major postoperative complications

\begin{tabular}{|c|c|c|c|c|c|c|}
\hline & \multicolumn{2}{|r|}{ AVR } & \multicolumn{2}{|r|}{ MVR } & \multicolumn{2}{|r|}{ Total } \\
\hline & $\mathbf{n}$ & $\%$ patient-years & n & $\%$ patient-years & $\mathbf{n}$ & $\%$ patient-years \\
\hline Late deaths & 128 & $2.94 \pm 0.26$ & 41 & $1.93 \pm 0.30$ & 169 & $2.61 \pm 0.20$ \\
\hline Valve related & 15 & $0.34 \pm 0.09$ & 7 & $0.33 \pm 0.12$ & 22 & $0.34 \pm 0.07$ \\
\hline Embolism & 17 & $0.39 \pm 0.09$ & 5 & $0.24 \pm 0.11$ & 22 & $0.34 \pm 0.07$ \\
\hline Fatal & 6 & $0.14 \pm 0.06$ & 2 & $0.09 \pm 0.07$ & 8 & $0.12 \pm 0.04$ \\
\hline Valve thrombosis & 6 & $0.14 \pm 0.06$ & 一 & - & 6 & $0.09 \pm 0.04$ \\
\hline Fatal & 3 & $0.07 \pm 0.04$ & - & - & 3 & $0.05 \pm 0.03$ \\
\hline Hemorrhages & 10 & $0.23 \pm 0.07$ & 3 & $0.14 \pm 0.08$ & 13 & $0.20 \pm 0.06$ \\
\hline Fatal & 4 & $0.09 \pm 0.05$ & 1 & $0.05 \pm 0.05$ & 5 & $0.08 \pm 0.04$ \\
\hline Periprosthetic leak & 1 & $0.02 \pm 0.02$ & 一 & - & 1 & $0.02 \pm 0.02$ \\
\hline Endocarditis & - & - & 1 & $0.05 \pm 0.05$ & 1 & $0.02 \pm 0.02$ \\
\hline Reoperation & 5 & $0.11 \pm 0.05$ & - & - & 5 & $0.08 \pm 0.03$ \\
\hline Overall valve-related complications & 35 & $0.80 \pm 0.14$ & 12 & $0.56 \pm 0.16$ & 47 & $0.73 \pm 011$ \\
\hline
\end{tabular}

$A V R$, Aortic valve replacement; $M V R$, mitral valve replacement.

in 22 (17 AVR and 5 MVR), valve thrombosis in 6 (all AVR), anticoagulant-related hemorrhages in 13 (10 AVR and $3 \mathrm{MVR}$ ), sudden unexpected death in 4 (1 AVR and $3 \mathrm{MVR}$ ), endocarditis (1 MVR), and periprosthetic leak (1 AVR). Actuarial freedom from overall prosthesis-related complications is $93 \% \pm 2 \%$ at 10 years and $82 \% \pm 5 \%$ at 17 years after AVR and $96 \% \pm 2 \%$ at 10 years and $86 \% \pm 5 \%$ at 17 years after MVR.

\section{DISCUSSION}

Evaluation of the performance of any cardiac valve substitute requires continuous patient monitoring and follow-up to obtain meaningful data, especially on the incidence of valve-related complications. This applies particularly to recipients of mechanical valves, which are significantly more prone to specific complications such as valve thrombosis and systemic embolic accidents than their biological prostheses counterparts. For this reason, data collected on extended follow-up of patients receiving mechanical prostheses seem of paramount importance to

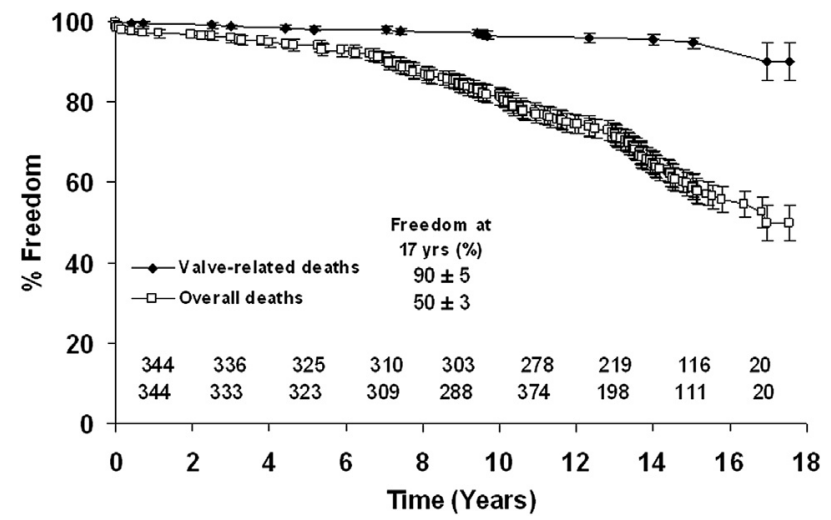

FIGURE 1. Actuarial survival and freedom from valve-related deaths after aortic valve replacement with the Sorin Bicarbon prosthesis. Numbers on the horizontal axis indicate patients at risk at each time interval. assess the overall performance of any given device in the long term. The SBP has been available for clinical use for more than 3 decades but, despite the high number of these valves implanted worldwide, data on very long-term follow-up are scarce. The recent update of a European multicenter study ${ }^{11}$ presented clinical outcomes of SBP recipients at 15 years, indicating that the SBP continues to perform satisfactorily even beyond the $10^{-}$year limit reached in other studies. 9,15

This article presents our experience with the SBP from a single center, thus eliminating the potential bias of methods and data collection from different institutions and therefore providing more reliable information derived from an extended follow-up; in our series, the mean follow-up was more than 12 years for both AVR and MVR patients with a maximum follow-up of more than 17 years. Operative mortality was low, less than $3 \%$ in the entire series, despite a high mean age and almost $30 \%$ of patients had an associated procedure; furthermore, no early deaths were valve related. Late survival was also extremely gratifying,

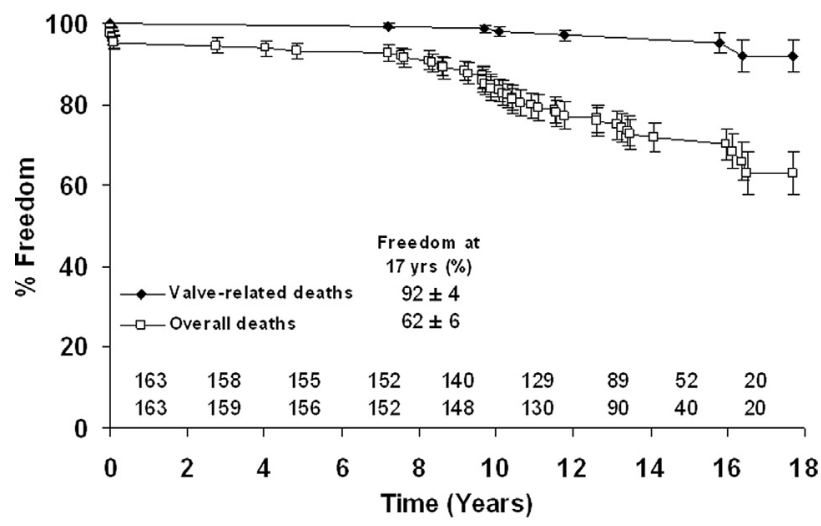

FIGURE 2. Actuarial survival and freedom from valve-related deaths after mitral valve replacement with the Sorin Bicarbon prosthesis. Numbers on the horizontal axis indicate patients at risk at each time interval. 


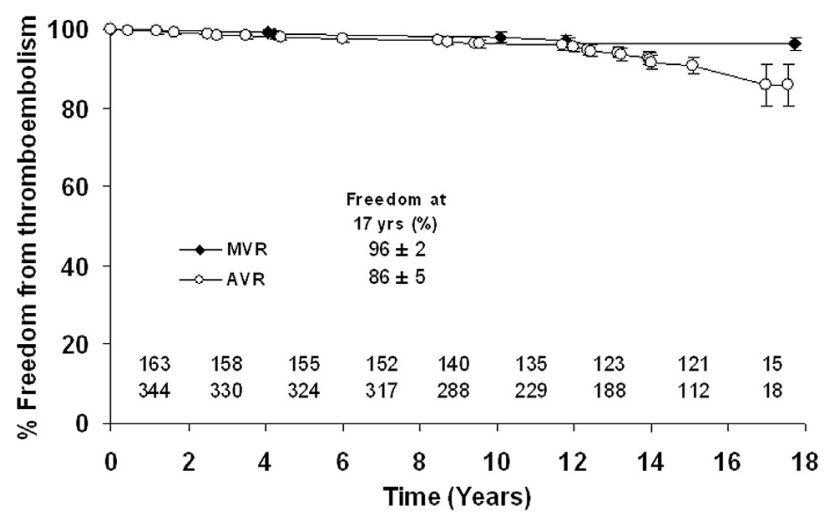

FIGURE 3. Actuarial freedom from thromboembolic episodes after aortic $(A V R)$ and mitral $(M V R)$ valve replacement with the Sorin Bicarbon prosthesis. Numbers on the horizontal axis indicate patients at risk at each time interval.

comparing favorably with data on the SBP reported by others $^{8-11}$ and with a clinical benefit in the long-term survivors as shown by the significant improvement in functional class; furthermore, late survival seems to be superior to that observed with other bileaflet prostheses in younger patient populations. ${ }^{16-18}$ Late mortality is usually considered to be independent of the type of prosthesis used, and is mostly influenced by patient selection, preoperative clinical status, and associated comorbidities. $^{19,20}$ The low incidence of prosthesisrelated late deaths with a linearized incidence of $0.34 \%$ $\pm 0.07 \%$ /patient-year and an actuarial freedom at 17 years of $90 \%$ for AVR and $92 \%$ for MVR is nevertheless noteworthy.

Thromboembolic complications are a continuous concern in recipients of mechanical prostheses. In the present series, however, a low incidence of embolic events was observed with a linearized incidence of $0.39 \% \pm 0.09 \% /$ patientyears after AVR and 0.24\% $\pm 0.11 \%$ /patient-years after MVR with an actuarial freedom from thromboembolism, including valve thrombosis, of $86 \%$ and $96 \%$, respectively, after AVR and MVR at 17 years, indicating that the innovative changes incorporated into the SBP design, improving transprosthetic flow and reducing turbulence, might positively influence its thrombogenicity. These figures compare favorably with those reported for the same device at shorter follow-up intervals ${ }^{8-11}$ and are similar or even superior to those observed with other bileaflet prostheses ${ }^{16-18,21-23}$; according to Ikonomidis and colleagues, ${ }^{17}$ the incidence of reported thromboembolism with the St Jude Medical prosthesis ranges from $0.8 \%$ to $3.5 \%$ /patient-year. A low rate of thromboembolism has also been reported with the On-X bileaflet mechanical prosthesis. Chan and colleagues ${ }^{24}$ observed an incidence of thromboembolism of $0.94 \%$ /patient-year after AVR and $0.72 \%$ /patient-year after MVR; Chambers and colleagues ${ }^{25}$ reported that this complication occurred with an incidence of $0.6 \%$ patient-year and $1.0 \% /$ patient-year late after AVR and MVR, respectively. As also noted by others, ${ }^{17}$ we have observed a disturbing incidence (6 episodes) of SBP thrombosis in AVR patients; this complication did not occur in MVR patients. We do not have a clear explanation for such outcomes, which are contrary to what has been reported in the literature. In our long-term survivors, we collected data on INR and found that the mean values were within the desired limits at the last follow-up, as currently suggested. $^{26}$ Embolic episodes and valve thrombosis occurred despite an INR within the planned target values; this apparent paradox, as observed by others, ${ }^{10}$ is difficult to explain but the role of other factors that could have contributed to such events must be considered. The presence of an enlarged left atrium or a dilated left ventricle has not been thoroughly analyzed, and the impact of other specific patient-related factors, as suggested by Butchart and colleagues, ${ }^{27}$ could not be assessed retrospectively. Thus, the fact that INR values were within the target range and that most patients were in sinus rhythm at the time of the event makes the unusual incidence of prosthetic thrombosis after AVR more difficult to understand. It must be also recognized that maintenance of stable INR values is often difficult to achieve and even mild variations in the intensity of anticoagulation are almost impossible to predict, thus limiting the relevance of our data on INR values. Mechanical valve recipients require life-long strict and carefully controlled warfarin treatment but, despite this, anticoagulant-related hemorrhages are still a major problem in these patients. Although this complication in our patient subset was low, with an actuarial freedom at 17 years of more than $95 \%$ in both groups, the occurrence of fatal bleeding, albeit limited, is still disturbing, indicating that the optimal intensity of oral anticoagulant therapy in patients with mechanical prostheses is still a matter of debate. $^{26,28-30}$

We have also found that other major postoperative complications, such as endocarditis and periprosthetic, leak are extremely uncommon after AVR and MVR with the SBP; moreover, no cases of structural failure were recorded, as also observed by others with the SBP as well as other bileaflet valves, ${ }^{10,11,16,21}$ thus confirming that the current generation of mechanical prostheses provides valve substitutes resistant to wear and mechanical stresses over time. In the present experience, the need for reoperation for all causes was also extremely low, with an incidence of $0.08 \%$ /patient-year, similar to other reports on various models of mechanical prostheses. ${ }^{11,17,21,22}$

The major limitation of this paper is that it is an observational retrospective study; however, it has the advantage of reporting data from a single center on a large number of patients, accurately reevaluated and with almost complete follow-up with few patients untraced. 
This allowed us to collect meaningful data on the performance of the SBP in the long term. Furthermore, we have not provided information on the hemodynamic behavior of this prosthesis. Previous reports have indicated that the SBP has an excellent hemodynamic performance both in vitro and in vivo with lower transvalvular gradients compared with other similar prostheses. ${ }^{31-33}$ Data from our group have already shown that, for the small sizes, the SBP is associated with low gradients, significant regression of left ventricular mass after AVR, and, more importantly, the absence of prosthesis-patient mismatch. ${ }^{34}$ Another issue that is not considered in this report concerns the occurrence of hemolysis. Subclinical hemolysis is frequently observed in normally functioning mechanical prostheses; this problem was addressed previously and it was shown that in patients with an SBP, the incidence of hemolysis was extremely low and even less frequent than observed with other bileaflet valves. ${ }^{11,35}$

In conclusion, our results indicate that the SBP continues to show an excellent overall performance up to 17 years postoperatively, as indicated by the significant clinical improvement achieved, the low incidence of postoperative adverse events, and a gratifying freedom from major valve-related complications in the long term. Therefore, based on the present experience, we conclude that the SBP remains a reliable and valid option whenever a mechanical prosthesis is indicated for both AVR and MVR.

\section{References}

1. Arom KV, Nicoloff DM, Kersten TE, Northrup WF, Lindsay WG, Emery RW. Ten years' experience with the St. Jude Medical valve prosthesis. Ann Thorac Surg. 1989;47:831-7.

2. de Luca L, Vitale N, Giannolo B, Cafarella G, Piazza L, Cotrufo M. Mid-term follow-up after heart valve replacement with CarboMedics bileaflet prosthesis. J Thorac Cardiovasc Surg. 1993;106:1158-65.

3. Ibrahim M, O'Kane H, Cleland J, Gladstone D, Sarzam M, Patterson C. The St. Jude Medical prosthesis. J Thorac Cardiovasc Surg. 1994;108:221-30.

4. Westaby S, Van Nooten G, Sharif H, Pillai R, Caes F. Valve replacement with the ATS open pivot bileaflet prosthesis. Eur J Cardiothorac Surg. 1996;10:660-5.

5. Casselman F, Herijgers P, Meyns B, Flameng W, Daenen W. The Bicarbon heart valve prosthesis: short-term results. J Heart Valve Dis. 1997;6:410-5.

6. Borman JB, Brands WGB, Camileri L, Cotrufo M, Daenen W, Gandjbakhch I, et al. Bicarbon valve - European multicenter clinical evaluation. Eur J Cardiothorac Surg. 1998;13:685-93.

7. Goldsmith I, Lip GYH, Patel RL. Evaluation of the Sorin Bicarbon bileaflet valve in 488 patients (519 prostheses). Am J Cardiol. 1999:83:1069-74.

8. Bortolotti U, Milano A, D’Alfonso A, Piccin C, Mecozzi G, Magagna P, et al. Evaluation of valve-related complications in patients with Sorin Bicarbon prosthesis: a seven-year experience. J Heart Valve Dis. 2001;10:795-801.

9. Borman JB, De Riberolles C. Sorin Bicarbon bileaflet valve: a 10-year experience. Eur J Cardiothorac Surg. 2003;23:86-92.

10. Vitale N, Cappabianca G, Visicchio G, Fondacone C, Paradiso V, Mannatrizio G, et al. Midterm evaluation of the Sorin Bicarbon heart valve prosthesis: single-center experience. Ann Thorac Surg. 2004;77:527-31.

11. Azarnoush K, Laborde F, de Riberolles C. The Sorin Bicarbon over 15 years clinical outcomes: multicentre experience in 1704 patients. Eur J Cardiothorac Surg. 2010;38:759-66.

12. Vallana F, Rinaldi S, Galletti M, Nguyen A, Piwnica A. Pivot design in bileaflet valves. ASAIO J. 1992;38:M600-6.
13. Arru P, Rinaldi S, Stacchino C, Vallana F. Relationship between some design characteristics and wear in the Bicarbon heart valve prosthesis. Int J Artif Organs. 1994; 17:280-93.

14. Akins CW, Miller DC, Turina MI, Kouchoukos NT, Blackstone EH, Grunkemeier GL, et al. Guidelines for reporting mortality and morbidity after cardiac valve interventions. J Thorac Cardiovasc Surg. 2008;135:732-8.

15. Whitaker DC, James SE, Ealesby RK. A single-center experience of the Sorin Bicarbon heart valve prosthesis: long-term clinical, haematological and hemodynamic results. J Heart Valve Dis. 2004;13:97-102.

16. Zellner JL, Kratz JM, Crumbley AJ III, Stroud MR, Bradley SM, Sade RM, et al. Long-term experience with the St. Jude Medical valve prosthesis. Ann Thorac Surg. 1999;68:1210-8.

17. Ikonomidis JS, Kratz JM, Crumbley AJ, Stroud MR, Bradley SM, Sade RM, et al. Twenty-year experience with the St. Jude Medical mechanical prosthesis. J Thorac Cardiovasc Surg. 2003;126:2022-31.

18. Emery RW, Krogh CC, Arom KV, Emery AM, Benyo-Albrecht K, Joyce LD, et al. The St. Jude Medical cardiac valve prosthesis: a 25-year-experience with single valve replacement. Ann Thorac Surg. 2005;79:776-82.

19. Tominaga R, Kurisu K, Ochiai Y, Tomita Y, Masuda M, Morita S, et al. A 10-year experience with the Carbomedics cardiac prosthesis. Ann Thorac Surg. 2005;79: 784-9.

20. Aagard J, Tingleff J. Fifteen year's clinical experience with the CarboMedics prosthetic heart valve. J Heart Valve Dis. 2005;14:82-8.

21. Kang CH, Ahn H, Kim KH, Kim KB. Long-term results of 1144 CarboMedics mechanical valve implantations. Ann Thorac Surg. 2005;79:1939-44.

22. Bryan AJ, Rogers CA, Bayliss K, Wild J, Angelini GD. Prospective randomized comparison of CarboMedics and St. Jude Medical bileaflet mechanical heart valve prostheses: ten-year follow-up. J Thorac Cardiovasc Surg. 2007;133: 614-22.

23. Toole MJ, Stroud MR, Kratz JM, Crumbley AJ, Bradley SM, Crawford FA, et al. Twenty-five year experience with the St. Jude Medical mechanical valve prosthesis. Ann Thorac Surg. 2010;89:1402-9.

24. Chen V, Jamieson WRE, Lam BK, Ruel M, Ling H, Fradet G, et al. Influence of the On-X mechanical prosthesis on intermediate-term major thromboembolism and hemorrhage: a prospective multicenter study. J Thorac Cardiovasc Surg. 2010;140:1053-8.

25. Chambers JB, Pomar JL, Mestres CA, Palatianos GM. Clinical event rates with the On.X bileaflet mechanical heart valve: a multicenter experience with follow-up to 12 years. J Thorac Cardiovasc Surg. 2013;145:420-4.

26. Van Nooten GJ, Caes F, Francois K, Van Belleghem Y, Bovè T, Vandenplas G, et al. Twenty years' single-center experience with mechanical heart valves: a critical review of anticoagulation policy. J Heart Valve Dis. 2012;21:88-98.

27. Butchart EG, Ionescu A, Payne N, Giddings J, Grunkemeier GL, Fraser AG. A new scoring system to determine thromboembolic risk after heart valve replacement. Circulation. 2003;108(Suppl II):II68-74.

28. Edmunds LH Jr. Thrombotic and bleeding complications of prosthetic heart valves. Ann Thorac Surg. 1987;44:430-45.

29. Cannegieter SC, Rosendaal FR, Wintzen AR, van der Meer FJM, Vandenbrouke JP, Briet E. Optimal oral anticoagulant therapy in patients with mechanical heart valves. N Engl J Med. 1995;333:11-7.

30. Bayliss A, Faber P, Dunning J, Ronald A. What is the optimal level of anticoagulation in adult patients receiving warfarin following implantation of a mechanical prosthetic mitral valve? Eur J Cardiothorac Surg. 2007;6:390-6.

31. Reul H, Van Son JA, Steinseifer U, Schmitz B, Schmidt A, Schmitz C, et al. In vitro comparison of bileaflet aortic heart valves prostheses. St. Jude Medical, CarboMedics, modified Edwards-Duromedics and Sorin-Bicarbon valves. J Thorac Cardiovasc Surg. 1993;106:412-20.

32. Grigioni M, Daniale C, D'Avenio G, Barbaro V. Hemodynamic performance of small-size bileaflet valves: pressure drop and laser Doppler anemometry study comparison of three prostheses. Artif Organs. 2000;24:959-65.

33. Kadir I, Wan IYP, Walsh C, Wilde P, Bryan AJ, Angelini G. Hemodynamic performance of the 21-mm Sorin Bicarbon mechanical aortic prosthesis using dobutamine Doppler echocardiography. Ann Thorac Surg. 2001;72:49-53.

34. De Carlo M, Milano AD, Nardi C, Mecozzi G, Bortolotti U. Serial Doppler echocardiographic evaluation of small-sized Sorin Bicarbon prostheses. J Thorac Cardiovasc Surg. 2003;126:337-43

35. Mecozzi G, Milano AD, De Carlo M, Sorrentino F, Pratali S, Nardi C, et al. Intravascular hemolysis in patients with new-generation prosthetic heart valves: a prospective study. J Thorac Cardiovasc Surg. 2002;123:550-6. 